\title{
Research on Influence of Digital Economy on Taxation
}

\author{
Pinna Li \\ Hubei University of Science and Technology, Xianning, 437100, China
}

\begin{abstract}
The rapid development of digital economy has brought new subjects to the traditional economic model. This paper firstly demonstrates the necessity of tax collection in the digital economy environment and then analyses the impact of the digital economy on taxation, including challenges and opportunities, in order to provide some references for the relevant researchers.
\end{abstract}

Keywords: digital economy, taxation, tax

\section{Concept of digital economy}

Digital economy refers to an economic system. In this system, digital technology has been widely used and has brought about the fundamental changes in the economic environment and economic activities. Digital economy is also a new social and political and economic system with digital information and business activities. Transactions between businesses, consumers and governments are growing rapidly through the Internet. The digital economy mainly studies the production, distribution and sales of goods and services that rely on digital technology. The business model of digital economy works well in itself, as it creates a win-win situation for both the enterprise and the consumer. The digital economy is not limited to e-commerce, including e-commerce, Internet plus and the digital economy three progressive stages. Digital economy is by no mere electronic commerce. Digital economy is a set of digital technology in the field of traditional economic communication, integration of the formation of a new economic form. Digital economy not only promote the development of social economy, and ultimately improve the quality of our overall economic and social, 
increased consumption. Digital economy plays a great role in solving the balanced development of the east and the west of China.

\section{Necessity of taxation on digital economy}

From the practice at home and abroad, assuming that countries do not have to provide such a relaxed space for e-commerce, it will not form today's world digital economy development pattern. However, from the domestic tax environment, assuming that e-commerce is not taxable or tax administration is too loose, it will lead to unfair, because the real economy suffered a relatively more tax cost and the formation of competitive disadvantage, and ultimately to be out of the road. At present, China's commercial environment, this phenomenon exists. The impact of the real economy is also derived from the tax, such as shop rent, labor and other operating costs of the pressure. Theoretically, no matter what kind of business model, for the same taxable items should be levied the same tax, so as to achieve the horizontal fairness of the tax. From the international tax environment, cross-border e-commerce tax issues, has been a hot spot in international taxation. In the cross-border trade, the principle of consumption is usually adopted to levy taxes, so as to avoid international double taxation. However, it is difficult to apply this principle to the taxation of electronic commerce. On one hand, the flow of transactions needs to have a certain degree of physical tracking difficult. On the other hand, the customs cannot confirm the part of the export. It is difficult to tax exemption and also difficult to levy taxes on their imports. Hangzhou's G20 summit put forward the development idea of global digital economy, further concerned about the impact of digital economy on the business model of multinational companies, the integration of global value chains, and the tax base erosion and profit transfer effect. Therefore, in the future with the further development of the digital economy, the form is more complex. How to make it and the real economy to achieve a fair tax burden is a question worth exploring. But I believe that the trend of digital economic development gradually become the norm by the new things, if you give up their taxes, in addition to equity issues, the tax revenue of a country will cause a great loss. Therefore, we should adhere to the principle of universal collection.

\section{Challenges of taxation on digital economy}

\subsection{Transformation of ecnomic subjects}

Under the traditional economic model, the main economic activity is the basic organization mode of enterprise. The enterprise cluster is a variety of factors of production in space, the pyramid operation management. In this mode, the natural person is mainly through the enterprise employment to obtain the reward of human capital. Natural person's savings into investment mainly rely on financial institutions, and enterprises are the main body of private consumption to the natural person. Therefore, the traditional economic model of enterprises is the 
main target of tax collection and management, in order to transfer tax as the main body of the country, enterprise taxpayers is even more important. However, the transaction cost of the development of the digital economy leads to a decrease of the necessity of making production agglomeration in space is greatly reduced, the traditional bureaucracy of large enterprises is being more flexible mode of combination of production factors instead, despite the presence of economies of scale will still maintain the efficiency advantage of large enterprises, but more emphasis on creative industries and facing the diverse needs of the field of small batch, relying on digital technology and network economy platform economy is on the rise. The development of shared economy has further resulted in the fuzziness of the natural person as the consumer and the producer. The market environment and the technical conditions of the individual direct transaction of the individual are also becoming more and more mature. The above development trend is bound to bring a great challenge to the tax collection and management system which is based on the enterprise taxpayer. In recent years, the tax authorities have faced to management problems of natural person tax registration for non-business platform in the face of the use of private cars to run full-time part-time or even personal tax.

\subsection{Transformation of trading objects}

The digital economy has the extensive penetration of the various economic sectors, the high dependence on intangible assets. It can accelerate the integration of corporate influence in global value chain, as the tax base erosion and profit transfer in the hardest hit. Network, virtual currency, three-dimensional printing, sharing economy and digital economy produce a new operation model. The operation mode relies more on intangible assets, the low tax regions to become very easy, and the tax collection system and it is difficult to keep up with. Digital economy is a common problem faced by all countries. If there is a specific kind, taking the Chinese consumers in the United States Amazon buys a book as an example, this is to go through customs, the problem is relatively easy to solve. But now there are a lot of intangible product transactions, such as software design, copyright transactions, it is difficult to achieve the above monitoring. There are differences in the attitude of the world to such as electronic commerce. The vast majority of cross-border transactions are carried out between affiliated enterprises and the unfair transfer pricing between affiliated companies is one of the main ways to avoid tax. As to the regulation of the transfer pricing, the tax law requires the adjustment of the transaction price in the same or similar condition as the independent enterprise, which is the independent transaction principle. The principle of independent trade is currently the main rules adopted by all countries in the transfer pricing legislation, the key factor to implement this principle is whether similar transactions exist to identify independent enterprises and related enterprises and between independent enterprises. It is more biased in favor of ecommerce, with the traditional line of commodity trading, as the same tax standards to treat. In recent years, with the growth in the scale of e-commerce, the 
United States hopes to be able to tax. It is a real problem that different states in the United States apply different tax laws.

\section{Opportunities of taxation on digital economy}

\subsection{Application of information sharing}

The improvement of information gathering and processing efficiency brought by the development of digital economy also provides a technical basis for the fundamental reform of tax collection and management. The core problem of tax collection is the asymmetric information of two types: one is the information asymmetry in the tax system and policy of the taxpayers and tax authorities, as a result of the complexity of tax system and tax declaration system is established, for small and medium-sized taxpayers and natural person taxpayers, this information asymmetry has a direct impact on the taxpayers pay tax in accordance with the ability to improve. The tax authorities need to provide quality service to tax relief; two is in the tax information, tax payers are more understanding of their transaction information, the information asymmetry exists between tax authorities and taxpayers. This requires the tax authorities through the tax assessment, tax audit, risk identification and punishment to find false tax information and promote the taxpayer compliance initiative. From the present stage, the development of the digital economy has a direct effect on the mitigation of these two types of information asymmetry. The tax service, tax authorities use the network, electronic payment and other means to provide comprehensive, timely, unified, high quality and low marginal cost of tax service and tax payment service uncertainty conditions gradually mature. If we can solve the information sharing system barriers and effectively control the risk, the development of digital economy will provide a strong support for the modernization of tax collection and management.

\subsection{Application of electronic invoice}

Electronic invoice is the product of the information age, the same as ordinary invoices, the tax bureau issued a unified form for businesses to use, the unified national invoice number encoding, using the unified anti-counterfeiting technology, distributed to businesses, with electronic signature mechanism in electronic tax bureau on the invoice. Electronic invoices in storage, query, access to more convenient, but also facilitate the e-commerce website to provide more convenient services for consumers. And can reduce the waste of resources on paper invoices, will reduce deforestation, more environmental protection, in line with the future development of human beings. The current use of digital economy and electronic commerce vigorously promote electronic invoicing is an important measure to improve the tax information collection and processing. The author believes that the promotion of electronic invoice can not only be regarded as an upgrade version of the paper invoice or network invoice, but to get rid of the traditional idea of the ticket management tax. At the same time with the invoice 
vouchers, accounting vouchers and commercial tax management tools three functions, corresponding to the three functions is a real transaction. The invoice after two is attached to the additional function of commercial vouchers. The implementation of electronic invoices should focus on the real deal records as a commercial function, integration and integration to achieve trading, payment, logistics information. The future use of networking technology, block chain technology can also be with the goods and services of authentication and traceability system linked. Therefore, the electronic invoice should be located in the micro economic activities of the main body of the real transaction information between the carrier, at the same time pay attention to the role of the financial accounting as an expense account and the original voucher. Only on this basis, the electronic invoice can provide a solid foundation for the modernization of tax collection and management.

\section{Conclusion}

Digital economy affects the development models of traditional economic. The traditional taxation faces many opportunities and challenges in the era of digital economy. The traditional model of tax collection is bound to have a series of changes. We should seize the opportunity and meet the challenge to accelerate the taxation system reform under the condition of the digital economy.

\section{References}

[1] Guo Xinjie, Zhang Bo, Gao Liqun, Challenges and Strategies for International Taxation in the Digital Economy, International Taxation in China, 28(3), pp.6-11, 2015.

[2] Zhang Zeping, Economic Allegiance Principle in the Allocation of International Tax Jurisdiction, Academic Monthly, 59(2), pp. 84-92, 2016.

[3] Zhang Zhiyong, Digital Economy and the Reform of International Tax Law: Paths and Plans, Journal of International Economic Law, 21(3), pp. 198-222, 2014.

[4] Shen Yali, Lin Beixin, Liao Weimin, A study on the Status Quo and the Approach of Multinationals' Tax Evasion and Tax Avoidance in China and the Prevention Strategies under the Background of Digital Economy, Journal of Yunnan University of Finance and Economics, 31(6), pp. 135-142, 2015. 